Obere Extremität 2018 $\cdot 13: 211-217$ https://doi.org/10.1007/s11678-018-0451-7 Received: 16 December 2017

Accepted: 9 February 2018

Published online: 12 March 2018

(c) The Author(s) 2018. This article is an open access publication.

CrossMark
Florian Dussing' Fabian Plachel $^{1,2}$ - Teresa Grossauer ${ }^{1}$ Thomas Hoffelner' . Eva Schulz ${ }^{1}$ Arvind von Keudell ${ }^{3}$ - Alexander Auffarth ${ }^{1} \cdot$ Philipp Moroder ${ }^{1,2}$ 'Department of Traumatology and Sports Injuries, Paracelsus Medical University, Salzburg, Austria ${ }^{2}$ Department for Shoulder and Elbow Surgery, Center for Musculoskeletal Surgery, Charitè Universitätsmedizin Berlin, Berlin, Germany

${ }^{3}$ Department of Orthopaedic Surgery, Brigham and Women's Hospital, Harvard Medical School, Boston, USA

\section{Anterior shoulder dislocation and concomitant fracture of the greater tuberosity} Clinical and radiological results
We hypothesized that concomitant isolated fractures of the greater tuberosity are associated with low rates of recurrent dislocation but decreased range of motion (ROM) after primary traumatic anterior shoulder instability, as repeatedly mentioned in the literature $[7,8$, 12]. The purpose of this study was to retrospectively evaluate the clinical and radiological outcome of patients treated for anterior glenohumeral (GH) dislocation in combination with an isolated fracture of the GT who underwent either surgical or nonsurgical treatment.

\section{Patients and methods}

The current investigation is a retrospective cohort study, approved by the institutional ethics committee (415-EP/73/5012014).

\section{Study population}

We conducted a retrospective review of the institutional shoulder database. We included all patients with (1) traumatic anterior shoulder dislocation in association with an (2) isolated fracture of the GT, and a (3) minimum follow-up (FU) of 2 years. Exclusion criteria were: (1) any other fracture of the proximal humerus or the glenoid, (2) previous surgical intervention to the affected shoulder, and (3) pre-existing neurological or muscular deficiency affecting the injured shoulder. From July 2007 to July 2013, a cohort of 71 consecutive shoulders in 69 patients were identified. Five patients sustained another subsequent fracture of the proximal humerus due to a later traumatic event and were excluded from clinical $\mathrm{FU}$, leaving a study population of 66 consecutive shoulders in 64 patients. Of these, 39 were male patients (61\%) and 25 female patients (39\%). Reported
[9]. The degree of fragment displacement after reduction has been suggested to be a prognostic factor regarding restitution of shoulder function. While nondisplaced and minimally displaced fractures can be treated conservatively, surgical fixation is indicated for 3-5 $\mathrm{mm}$ of displacement, depending on the patient's age and activity level [9-11].

Level of evidence: level IV, case series with no comparison group. 

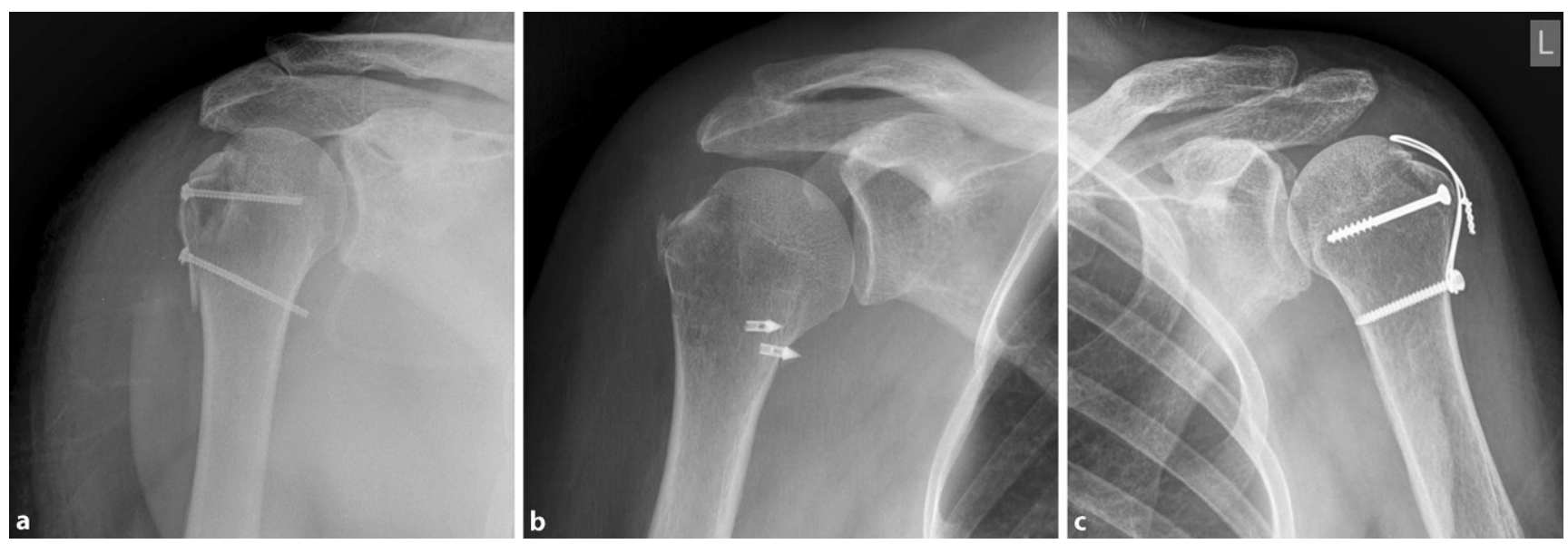

Fig. 1 ॥ Surgical fixation techniques: a percutaneous reduction and fixation using 3-mm cannulated self-tapping screws; b open reduction and fixation using sutures and suture anchors in a lateral single-row configuration; c screw fixation in combination with wire cerclages
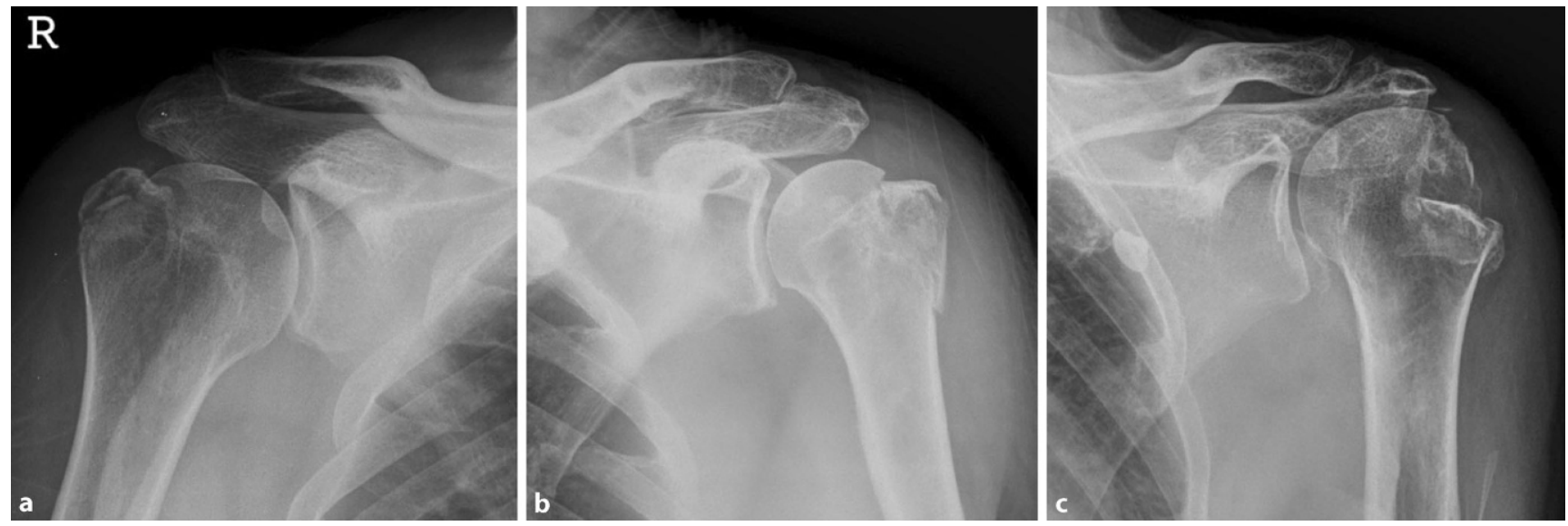

Fig. $2 \Delta$ Morphological classification for greater tuberosity fractures:a avulsion type fracture; $\mathbf{b}$ split type fracture; $\mathbf{c}$ depression type fracture [21]

causes of the trauma were: fall in a domestic setting $(n=25)$, winter sports accidents $(n=12)$, fall during leisure time activity without involvement of a vehicle $(n=9)$, bicycle accident $(n=9)$, motor vehicle accidents $(n=5)$, occupational accidents $(n=3)$, and epileptic seizure $(n=3)$.

In all, 53 patients ( 55 shoulders, $83 \%$ ) were available for FU. Five patients (8\%) died from an unrelated cause and six patients (9\%) could not be contacted because current contact information was lacking. Mean patient age at the time of the initial trauma was $56.5 \pm$ 14.4 years (range: $15-84$ years). The mean FU was $59.0 \pm 20.7$ months (range: 25-96 months).

The study population was divided into two groups according to treatment ap- proach: (1) nonsurgical group (37 cases, $67 \%$ ) and (2) surgical group (18 cases, 33\%; • Table 1).

\section{Patient care}

Our diagnostic and treatment protocol for patients with GH dislocation and concomitant GT fracture consisted of clinical examination followed by biplane radiographicimaging (true anteroposterior [a.p.] view and y-view) to confirm the diagnosis of $\mathrm{GH}$ dislocation and determine position of the humeral head and the fractured greater tuberosity. One careful attempt of closed reduction was usually performed in the emergency room with adequate analgesia. If unsuccessful, the $\mathrm{GH}$ dislocation was reduced with the patient under general anesthesia and relax- ation in the operating room to prevent the risk of iatrogenic humeral fractures $[13,14]$. Clinical examination and radiographic imaging were repeated to identify neurological changes and confirm the reduction as well as fracture morphology of the greater tuberosity. In the case of inconclusive radiographs, an additional computed tomography (CT) scan with three-dimensional (3D) reconstruction to evaluate the fracture morphology and degree of GT displacement was obtained (42 patients).

Nerve injury became evident in seven patients during the initial examination. Of these patients, four were found to have axillary nerve palsy, two had radial nerve palsy with one affecting the brachial plexus. All of them fully 
Obere Extremität 2018 $13: 211-217$ https://doi.org/10.1007/s11678-018-0451-7

(c) The Author(s) 2018. This article is an open access publication.

\section{F. Dussing · F. Plachel · T. Grossauer · T. Hoffelner · E. Schulz · A. von Keudell · A. Auffarth · P. Moroder}

\section{Anterior shoulder dislocation and concomitant fracture of the greater tuberosity. Clinical and radiological results}

\section{Abstract}

Background. Recurrence rates after primary traumatic shoulder dislocation are distinctly high. We hypothesized that concomitant isolated fractures of the greater tuberosity are associated with low rates of persistent instability but decreased range of motion. Methods. Between 2007 and 2013, 66 consecutive shoulders in 64 patients were treated for primary shoulder dislocation combined with an isolated fracture of the greater tuberosity with either a nonsurgical (48 shoulders, $72.7 \%$ ) or surgical (18 shoulders, $27.3 \%$ ) treatment approach. In all, 55 cases (83.3\%) were available for clinical follow-up examination after an average of $59.0 \pm 20.7$ months (range: 25-96 months) and of these, 48 (72.7\%) patients consented to radiological evaluation to determine healing and position of the greater tuberosity.

Results. The mean range of motion of the affected shoulder was significantly decreased by $9^{\circ}$ of elevation $(p=0.016), 11^{\circ}$ of abduction $(p=0.048), 9^{\circ}$ of external rotation in $0^{\circ}$ of abduction $(p=0.005)$, and $10^{\circ}$ of external rotation in $90^{\circ}$ of abduction $(p=0.001)$, compared with the unaffected shoulder. The mean WOSI score was $373 \pm 486$ points, the mean Constant and Murley score was $75.1 \pm 19.4$ points, and the mean Rowe score was $83 \pm 20$ points. Three cases (5.5\%) of redislocation were reported among the cohort, all of them were due to a relevant trauma.
Radiological evaluation revealed anatomically healed fragments in 31 shoulders (65\%), dislocation of the fragment in ten shoulders (21\%), impaction into the humeral head in four shoulders (8\%), and absorption in three shoulders (6\%).

Conclusion. A concomitant isolated fracture of the greater tuberosity leads to low recurrence rates along with a significant decrease in range of motion after primary traumatic anterior shoulder dislocation.

\section{Keywords}

Shoulder fractures - Conservative treatment . Surgery $\cdot$ Recurrence $\cdot$ Range of motion

\section{Schulterluxation mit begleitender Tuberculum-majus-Fraktur. Klinische und radiologische Ergebnisse}

\section{Zusammenfassung}

Hintergrund. Die Reluxationsrate nach erstmaliger traumatischer vorderer Schulterluxation ist generell hoch. Eine begleitende Fraktur des Tuberculum majus wird als protektiver Faktor angesehen, könnte jedoch einen negativen Einfluss auf den Bewegungsumfang haben.

Methodik. Zwischen 2007 und 2013 wurden 66 Schulterverletzungen mit dem genannten Verletzungsbild entweder nach konservativem (48 Schultern, 72,7\%) oder chirurgischem (18 Schultern, 27,3\%) Behandlungsansatz an der Abteilung der Autoren versorgt. Davon wurden 55 Schultern $(83,3 \%)$ klinisch und 48 (72,7\%) auch radiologisch nachuntersucht. Mittels detaillierter Anamnese, 4 klinischen Scores - Constant-Murley Score, WOSI (Western Ontario Shoulder Instability Index), Rowe Score, subjektiver Schulterwert (,subjective shoulder value", SVV) - und
Bestimmung des Bewegungsumfangs im Schultergelenk wurden Schulterfunktion und Schulterstabilität erhoben. Eine etwaige Dislokation des Tuberculum majus wurde mittels Röntgenaufnahmen in 3 Ebenen (a.-p., seitlich/Y-View, axial) analysiert.

Ergebnis. Der Bewegungsumfang der verletzten Schulter war im Vergleich zur Gegenseite durchschnittlich um $9^{\circ}(p=0,016)$ in der Elevation, um $11^{\circ}(p=0,048)$ in der Abduktion, um $9^{\circ}(p=0,005)$ in der Außenrotation aus Neutralstellung und um $10^{\circ}(p=0,001)$ in der Außenrotation aus $90^{\circ}$ Abduktion signifikant eingeschränkt. Der durchschnittliche WOSI-Score betrug $373 \pm$ 486 Punkte, der Constant-Murley Score betrug $75 \pm 19$ Punkte und der durchschnittliche Rowe Score betrug $83 \pm 20$ Punkte. In 3 Fällen $(5,5 \%)$ trat eine erneute Schulterluxation in der Kohorte auf, wobei sich 2 Fälle bilateral bei einem jugendlichen Epileptiker ereigneten. Die radiologische Auswertung ergab 31 (65\%) anatomisch eingeheilte Tuberkula, 10 Fälle ( $21 \%)$, in denen das Fragment disloziert war, 4 Fälle ( $8 \%)$, in denen das Tuberkulum in den Humerus impaktiert war, und 3 Fälle (6\%), in denen es zur Absorption des Bruchstücks gekommen war.

Schlussfolgerung. Eine begleitende isolierte Fraktur des Tuberculum majus verringert das Reluxationsrisiko nach vorderer Schulterluxation, führt jedoch gleichzeitig zu einer signifikanten Abnahme des Bewegungsumfangs.

Schlüsselwörter

Schulterfrakturen · Konservative Behandlung . Operation · Rezidiv · Bewegungsumfang recovered at a mean of 6 weeks after reduction.

Surgical treatment was indicated in (1) patients younger than 65 years of age and displacement greater than $3 \mathrm{~mm}$ and in (2) patients older than 65 years and displacement greater than $5 \mathrm{~mm}$ on initial CT, measuring the widest distance. Surgical treatment was furthermore indicated for patients with depression-type fractures and an irreducible fragment dis- location after reduction of the dislocated shoulder [10, 11].

Otherwise, nonsurgical treatment was advised, consisting of initial immobilization of the $\mathrm{GH}$ joint in internal rotation for 4 weeks with an arm sling and weekly clinical and radiological FU examination in our clinic to detect possible late displacement of the GT. This was followed by mobilization of the upper extremity under the guidance of a physical therapist starting with passive ROM and advancing at approximately 6 weeks to active ROM.

Surgical treatment was performed either via percutaneous reduction of the fracture and fixation using cannulated self-tapping 3-mm screws (7 cases; - Fig. 1a) or open reduction and fixation with either cannulated self-tapping 3 -mm screws or suture anchors (6 cases; - Fig. 1b) or screw fixation in combina- 
tion with steel-wire cerclages (5 cases; - Fig. 1c). All procedures were performed or supervised by a senior trauma surgeon. Postoperative care followed the conservative therapy protocol as described earlier.

\section{Clinical follow-up evaluation}

After obtaining informed consent, the clinical FU was conducted in our outpatient clinic by the principal investigator and supervised by a resident. All patients filled out a questionnaire in order to complete patient history comprehensively. The clinical outcome was determined using the subjective shoulder value (SSV; [15]), Western Ontario Shoulder Instability Index (WOSI; [16]), the Rowe scoring system (Rowe 1988; [17]), and the Constant and Murley score (CS; [18]). With regard to the heterogeneity of our study population, the "ageand gender-adjusted CS" was used [19]. The shoulder-related level of exertion in terms of work and sports was measured with the shoulder activity level (SAL; [20]). Current pain intensity was determined using a 10-part visual analogue scale (VAS 0-10).

Clinical examination included the assessment of the active ROM of both shoulders, which was measured with a goniometer including elevation, abduction $(\mathrm{ABD})$, external rotation (ER), and internal rotation (IR) in $0^{\circ}$ and $90^{\circ} \mathrm{ABD}$ position. Shoulder strength was assessed in $90^{\circ} \mathrm{ABD}$ position with an IDO isometer (IDO, Innovative Design Orthopaedics Limited, Redditch, Worcestershire, UK).

\section{Radiological evaluation}

The type of fracture on imaging following reduction was categorized according to the fragment's morphology into three groups applying a classification system for GT fractures [21]:

1. Avulsion fracture (- Fig. 2a), characterized by small fragments and the presence of a horizontal fracture line caused by a shearing motion of the GT along the glenoid rim and tension of the muscles of the RC.
2. Split fracture (๑ Fig. $\mathbf{2 b}$ ), characterized by relatively large fragments and almost vertical fracture line from impaction of the GT on the anterior side of the glenoid.

3. Depression-type fracture ( $\bullet$ Fig. 2c), characterized by impaction of the fragment into the humeral head due to collision with the anterior glenoid. Depression-type fractures are distinct from Hill-Sachs lesions as the GT is entirely impacted into the humeral head, while Hill-Sachs lesions affect the posterolateral articular surface of the humeral head [22].

At the final FU, three views of radiographic imaging were obtained (true a.p. view, axillary view, and $y$-view) to assess bony union, position, and displacement of the GT fragment and accurate articulation of the humeral head with the glenoid. Instability arthropathy was evaluated on true a.p. radiograph views of the shoulder according to the classification system of Samilson and Prieto [23]. FU images were compared with postreduction images to evaluate the development of instability arthropathy. We were able to radiographically examine 48 patients (73\%), of whom 32 had undergone nonsurgical treatment and 16 cases had undergone surgical repair. All radiographic analyses were performed by a radiologist and a trauma surgeon.

\section{Statistical analysis}

Statistical results were calculated with $\mathrm{IMB}^{\circledR}$ SPSS $^{\circledR}$ Statistics Version 21. For all values, descriptive statistics were applied, using the mean, standard deviation (SD), and minimum and maximum values, while the Kolmogorov-Smirnov test was used to test for normal distribution. Comparison of the variables was made by using Student's $t$-test for normally distributed data and the Mann-Whitney $U$ test for nonnormally distributed data. The Kruskal-Wallis test was used to compare nonnormally distributed variables when there were more than two groups.

Statistical analysis was made with twotailed $p$ values and the alpha level was set at 0.05 .

\section{Results}

\section{Clinical evaluation}

Clinical evaluation of 53 patients ( 55 shoulders) showed a mean CS of $75.1 \pm$ 19.4 points (range: $25-100$ points) and a mean age- and gender-adjusted CS of the affected shoulder of $94.2 \pm 25.2 \%$ (range: $31.1-128.9 \%$ ). The mean WOSI score was $373.2 \pm 486.2$ points (range: $0-2,078$ points) and the mean Rowe score was $82.6 \pm 19.5$ points (range: $28-100$ points). Pain intensity at $\mathrm{FU}$ averaged $1.6 \pm 2.3$ points (range: $0-8$ points). The mean reported SSV for the affected shoulder was $78.9 \% \pm 25.9 \%(10-100 \%)$. At FU the mean SAL reported by the study population was $1.6 \pm 1$ points (range: $0-4$ points), whereat two patients reached an SAL of 4 points, 11 patients an SAL of 3 points, 14 an SAL of 2 points, 19 an SAL of 1 point, and nine an SAL of 0 points.

The ROM measured at $\mathrm{FU}$ is presented in $\bullet$ Table 2. No statistically significant differences were detected between the nonsurgical and the surgical group in regard to ROM (elevation: $p=0.177$; ABD: $p=0.178$; ER neutral position: $p=0.703$; ER $90^{\circ}$ abduction: $p=0.651$; IR $90^{\circ}$ abduction: $p=0.307$ ).

The results of the clinical outcome scores are outlined in $\bullet$ Table 3.

No statistically significant difference was detected between the three GT fragment type groups regarding the ROM (elevation: $p=0.203$; ABD: $p=0.269$; ER neutral position: $p=0.797$; ER $90^{\circ}$ abduction: $p=0.313$; IR $90^{\circ}$ abduction: $p=0.701)$ and clinical outcome scores (CS: $p=0.807$; WOSI: $p=0.337$; ROWE: $p=0.691$; pain: $p=0.239$; SSV: $p=0.467$ ).

\section{Radiological evaluation}

Review of the radiographs made after reduction of the GH dislocation demonstrated $29(43.9 \%)$ avulsion type fractures, $26(39.4 \%)$ split type fractures, and 11 (16.7\%) impression type fractures according to the morphological properties [21] of the fractured tuberosity fragments (- Table 4).

Of the initially 20 undisplaced fractures among the nonsurgical group, 
Table 2 Mean ROM and loss of ROM of the affected (index) shoulder vs. the unaffected (contralateral) side in conservative and surgical treatment groups

\begin{tabular}{|c|c|c|c|c|c|c|c|c|}
\hline & \multicolumn{4}{|c|}{ Conservative $(n=37)$} & \multicolumn{4}{|c|}{ Surgical $(n=18)$} \\
\hline & $\begin{array}{l}\text { Mean } \\
\text { index }\end{array}$ & $\begin{array}{l}\text { Contra- } \\
\text { lateral }\end{array}$ & $\begin{array}{l}\text { Mean } \\
\text { loss }\end{array}$ & $p$ & $\begin{array}{l}\text { Mean } \\
\text { index }\end{array}$ & $\begin{array}{l}\text { Contra- } \\
\text { lateral }\end{array}$ & $\begin{array}{l}\text { Mean } \\
\text { loss }\end{array}$ & $p$ \\
\hline$E L$ & $145^{\circ}$ & $155^{\circ}$ & $10^{\circ}$ & $0.024^{*}$ & $151^{\circ}$ & $160^{\circ}$ & $9^{\circ}$ & 0.058 \\
\hline$A B D$ & $144^{\circ}$ & $156^{\circ}$ & $12^{\circ}$ & $0.037^{*}$ & $150^{\circ}$ & $161^{\circ}$ & $11^{\circ}$ & 0.174 \\
\hline$E R 0^{\circ}$ & $44^{\circ}$ & $53^{\circ}$ & $9^{\circ}$ & $0.037^{*}$ & $48^{\circ}$ & $59^{\circ}$ & $11^{\circ}$ & $0.027^{*}$ \\
\hline$E R 90^{\circ}$ & $63^{\circ}$ & $73^{\circ}$ & $10^{\circ}$ & $0.004^{*}$ & $67^{\circ}$ & $78^{\circ}$ & $11^{\circ}$ & $0.013^{*}$ \\
\hline $\operatorname{IR} 90^{\circ}$ & $44^{\circ}$ & $54^{\circ}$ & $8^{\circ}$ & 0.131 & $51^{\circ}$ & $58^{\circ}$ & $7^{\circ}$ & 0.396 \\
\hline
\end{tabular}

$R O M$ range of motion, EL elevation, $A B D$ abduction, $E R 0^{\circ}$ external rotation from neutral position, $E R 90^{\circ}$ external rotation from $90^{\circ}$ abduction position, $I R 90^{\circ}$ internal rotation from $90^{\circ}$ abduction position

*Statistically significant values $(p<0.05)$

Table 3 Comparison of clinical scores between surgical and conservative treatment subgroups

\begin{tabular}{|c|c|c|c|c|c|c|c|c|}
\hline & & \multicolumn{3}{|c|}{ Conservative $(n=37)$} & \multicolumn{3}{|c|}{ Surgical $(n=18)$} & \multirow[b]{2}{*}{$p$} \\
\hline & & Mean & SD & Range & Mean & SD & Range & \\
\hline \multirow[t]{5}{*}{ Score } & SSV & $79.7 \%$ & $27.7 \%$ & $10-100 \%$ & $80.94 \%$ & $20.7 \%$ & $30-100 \%$ & 0.656 \\
\hline & WOSI & 353.3 & 512.9 & $0-2078$ & 356.78 & 391.3 & $10-1040$ & 0.821 \\
\hline & ROWE & 82.5 & 20.3 & 28-100 & 79.89 & 18.65 & $45-100$ & 0.492 \\
\hline & CS & 75.0 & 20.0 & $25-100$ & 79.3 & 18.5 & 38-100 & 0.264 \\
\hline & CS_ag & 94.7 & 26.1 & $31-125$ & 94.4 & 21.1 & $45-129$ & 0.815 \\
\hline
\end{tabular}

SSV subjective shoulder value, WOSI Western Ontario Shoulder Instability Index, ROWE Rowe score, CS Constant-Murley score, CS_ag Constant score adjusted to age and gender, SD standard deviation

\begin{tabular}{|c|c|c|c|c|c|c|}
\hline \multirow[t]{2}{*}{ Fracture type } & \multicolumn{2}{|c|}{ Cohort $(n=66)$} & \multicolumn{2}{|c|}{ Conservative $(n=48)$} & \multicolumn{2}{|c|}{ Surgical $(n=18)$} \\
\hline & $n$ & $\%$ & $n$ & $\%$ & $n$ & $\%$ \\
\hline Avulsion & 29 & 43.9 & 23 & 47.9 & 6 & 33.3 \\
\hline Split & 26 & 39.4 & 17 & 35.4 & 9 & 50 \\
\hline Impression & 11 & 16.7 & 8 & 16.7 & 3 & 16.7 \\
\hline
\end{tabular}

\begin{tabular}{|c|c|c|c|c|c|c|c|}
\hline \multirow[t]{2}{*}{$\begin{array}{l}\text { Fragment } \\
\text { position }\end{array}$} & \multicolumn{2}{|l|}{$\begin{array}{l}\text { Cohort } \\
(n=48)\end{array}$} & \multicolumn{2}{|c|}{$\begin{array}{l}\text { Conservative } \\
(n=32)\end{array}$} & \multicolumn{3}{|l|}{$\begin{array}{l}\text { Surgical } \\
(n=16)\end{array}$} \\
\hline & $\begin{array}{l}\text { Follow- } \\
\text { up }\end{array}$ & Posttreat. & $\begin{array}{l}\text { Follow- } \\
\text { up }\end{array}$ & Postred. & $\begin{array}{l}\text { Follow- } \\
\text { up }\end{array}$ & Postsurg. & Presurg. \\
\hline Anatomical & 29 & 30 & 20 & 20 & 9 & 10 & 0 \\
\hline Absorption & 3 & 0 & 2 & 0 & 1 & 0 & 0 \\
\hline Dorsal & 6 & 7 & 3 & 4 & 3 & 3 & 8 \\
\hline Cranial & 0 & 2 & 0 & 2 & 0 & 0 & 2 \\
\hline Dorsocranial & 4 & 3 & 3 & 2 & 1 & 1 & 4 \\
\hline Impression & 6 & 6 & 4 & 4 & 2 & 2 & 2 \\
\hline
\end{tabular}

19 remained in anatomical position and one underwent absorption. Of the initially four dorsally displaced tuberosities, three remained dorsally displaced, whereas one was found to be displaced dorsocranially at final FU. Of the initially two cranially displaced tuberosities, one was found in anatomical position at $\mathrm{FU}$, whereas the other tuberosity was absorbed. Both dorsocranially displaced tuberosities showed no further evidence of subsequent displacement.

Review of postoperative radiographs in the surgical group showed three tuberosities with dorsal displacement, one tuberosity with dorsocranial displacement, and two impacted tuberosities, all of which remained in the same displaced position until final radiological FU. Of the ten anatomically reduced tuberosities, nine stayed in anatomical position at FU while one resorbed (- Table 5).

Arthropathy was graded as "none" in 38 shoulders $(79.2 \%)$, "mild" in eight shoulders (16.7\%), and "moderate" in two shoulders (4.2\%) of the conservative group on radiographs following reduction, while in the surgical group, arthropathy was graded "none" in all 18 shoulders. At FU, instability arthropathy among the conservative group was graded "none" in 18 shoulders $(52.9 \%)$, "mild" in 11 shoulders (32.4\%), and "moderate" in three shoulders (8.9\%). Among the surgical group, nine shoulders $(56.3 \%)$ were graded with "none" and seven shoulders (43.8\%) with "mild" instability arthropathy at FU.

\section{Revisions}

Revision surgery was necessary in five of 18 patients (27.8\%); all of them were treated with cannulated self-tapping 3-mm screws. One patient who was treated with percutaneous screws sustained screw breakage 13 days after surgery requiring revision surgery. Four other patients $(22.2 \%)$ underwent removal of surgical implants owing to material migration, which was performed after an average time of 116.5 days (73-167 days). No patient of the nonsurgical group was scheduled for secondary surgical reduction and stabilization of 
the fragment after conservative therapy regime was started.

\section{Re-dislocation}

Three cases $(5.5 \%)$ of traumatic re-dislocation were reported among the study population, of which two cases were related to an epileptic seizure (bilateral redislocation in one patient). One case occurred during a traumatic skiing accident as the patient fell onto the previously injured shoulder. The formerly fractured GT remained stable during this second dislocation episode. All of the cases were observed in the conservative group.

\section{Discussion}

The principal finding of the current study was that a concomitant isolated fracture of the greater tuberosity in cases with traumatic anterior shoulder dislocation was associated with a low recurrence rate but decreased ROM compared with the contralateral shoulder at mid-term FU.

In general, recurrent shoulder instability is the most common complication following primary shoulder dislocation with recurrence rates of up to $96 \%$ in adolescents [24]. Rates of recurrence are known to vary depending to a great degree upon the patient's age, with recurrence rates of $54 \%$ in patients below 30 years and $12 \%$ for older patients [25]. The recurrence rate in this study cohort was much lower. A possible explanation might be the presence of the concomitant tuberosity fracture in all cases, which seems to reduce the risk for recurrence as previously described [10]. Other possible explanations are that the concomitant fracture of the greater tuberosity reduces the joint compression forces during the dislocation episode, which in return reduces the risk for damage to the anterior glenoid rim and anterior capsulolabral structures. Another explanation might be the observed loss of end-range of motion, which can also reduce the risk for instability [9, 10]. ROM, especially in external rotation and abduction, was significantly decreased on the affected side of our study patients compared with the nonaffected shoulder. No differences in ROM were seen in cases with surgical treatment compared with cases with conservative therapy when the aforementioned surgical indication criteria were applied. The mean loss of external rotation of approximately $10^{\circ}$ in our study cohort is comparable to the outcomes after stabilization surgery for anterior shoulder instability [26].

The low recurrence rate of approximately $5.5 \%$ in the current study could partially also be explained by age-related factors. With increasing age, there is a higher risk of concomitant damage to bony structures such as the greater tuberosity during shoulder dislocation, which is most likely associated with reduced bone density at the proximal humerus. Therefore, in this study cohort primary shoulder dislocation occurred at an age of 40 years or older in about three out of four cases, which is much higher than the typically younger age at which primary traumatic dislocations occur [4]. Since the risk of recurrence decreases with increasing age at primary dislocation [5], the higher average age of the patients in this study can be considered as a confounder leading to a low recurrence rate.

Radiographic analysis at final FU revealed a low risk for secondary fragment displacement after both conservative and surgical treatment. In some cases, secondary fragment absorption was observed. Potential reasons for the absorption might be secondary dislocation with loss of strain on the tuberosity, lack of vascularity, or low-grade infection in the surgical cases.

Considering that the secondary displacement rate was low, the functional outcome was comparable, and the recurrence rate was low, conservative treatment in patients younger than 65 years and displacement less than $3 \mathrm{~mm}$ and in patients older than 65 years and displacement less than $5 \mathrm{~mm}$ seems to be justified, of course always taking into account the patient specific activity level, general health status, and severity of symptoms as well [27].

Evaluation of radiographs made after reduction of the $\mathrm{GH}$ dislocation with regard to morphological properties [21] of the fractured GT fragments demonstrated similar properties of avulsion type fragments (43.9\%) and split type fragments (39.4\%), whereas only a small proportion of impression type fractures were observed (16.7\%). The proportions show almost the same distribution as those presented by Mutch et al. in their study in 2014 of 199 cases (avulsion type, $39 \%$; split type, $41 \%$; impression type, $20 \%$; [21]). Statistical evaluation did not show any significant difference among these three subgroups regarding ROM and clinical outcome scores at FU.

\section{Limitations}

The study has limitations typical of retrospective investigations. A control group of primary dislocations without concomitant fracture of the greater tuberosity was not available. Moreover, CT measurements of the distance between the tuberosity fragment and the intact proximal humerus were not available in all cases. Measuring the dislocation distance on radiographs might have limited reliability. Furthermore, no ultrasound examination or magnetic resonance imaging of the $\mathrm{RC}$ was made at $\mathrm{FU}$, which could have offered more explanations for the loss of ROM.

Another limitation is the rather low number of surgical cases, which can result in a lack of statistical power when comparing results with the nonsurgical group.

\section{Practical conclusion}

\section{- Anterior GH dislocation with con- comitant isolated fracture of the GT results in diminished joint mobility but low recurrence of instability. - ROM in any direction was signifi- cantly decreased compared with the contralateral shoulder, regardless of whether the surgical or conservative treatment approach was followed.}




\section{Corresponding address}

F. Dussing, MD
Department of Traumatology
and Sports Injuries, Paracelsus
Medical University
Müllner Hauptstraße 48,
5020 Salzburg, Austria
florian.dussing@pmu.ac.at

Funding. Open access funding provided by Paracelsus Medical University.

\section{Compliance with ethical guidelines}

Conflict of interest. F. Dussing, F. Plachel, T. Grossauer, T. Hoffelner, E. Schulz, A. von Keudell, A. Auffarth, and P. Moroder declare that they have no competing interests.

All procedures performed in studies involving human participants were in accordance with the ethical standards of the institutional and/or national research committee and with the 1964 Helsinki declaration and its later amendments or comparable ethical standards. Informed consent was obtained from all individual participants included in the study. Ethical committee approval: Study number: 415-EP/73/501-2014.

Open Access This article is distributed under the terms of the Creative Commons Attribution 4.0 International License (http://creativecommons.org/licenses/by/ 4.0/), which permits unrestricted use, distribution, and reproduction in any medium, provided you give appropriate credit to the original author(s) and the source, provide a link to the Creative Commons license, and indicate if changes were made.

\section{References}

1. Zacchilli MA, Owens BD (2010) Epidemiology of shoulder dislocations presenting to emergency departments in the United States. J Bone Joint Surg Am 92(3):542. https://doi.org/10.2106/JBJS.I. 00450

2. Kroner K, Lind T, Jensen J, Krøner K, Lind T, Jensen J (1989) The epidemiology of shoulder dislocations. Arch Orthop Trauma Surg 108(5):288-290

3. Tas M, Canbora MK, Kose O, Egerci OF, Gem M (2013) Demographic and clinical characteristics of traumatic shoulder dislocations in an urban city of Turkey: a retrospective analysis of 208 cases. Acta Orthop Traumatol Turc 47(3):147-152. https://doi. org/10.3944/AOTT.2013.3090

4. Rowe CR (1956) Prognosis in dislocations of the shoulder. JBone Joint Surg Am 38-A (5):957-977

5. Olds $M$, Ellis $R$, Donaldson $K$, Parmar $P$, Kersten $P$ (2015) Risk factors which predispose first-time traumatic anterior shoulder dislocations to recurrent instability in adults: a systematic review and meta-analysis. Br J Sports Med 49(14):913-922. https://doi.org/10.1136/bjsports-2014-094342

6. MattyasovszkySG, BurkhartKJ, Ahlers Cetal (2011) Isolated fractures of the greater tuberosity of the proximal humerus: a long-term retrospective study of 30 patients. Acta Orthop 82(6):714-720. https://doi.org/10.1016/j.yort.2011.12.016

7. Kralinger FS, Golser K, Wischatta R, Wambacher M, Sperner G (2002) Predicting recurrence after primary anterior shoulder dislocation. Am J Sports Med 30(1):116-120. https://doi.org/10.1177/ 03635465020300010501

8. McLaughlin HL, MacLellan DI (1967) Recurrent anterior dislocation of the shoulder. II. A comparative study. JTrauma 7(2):191-201

9. Green A, Izzi J (2003) Isolated fractures of the greater tuberosity of the proximal humerus. J Shoulder Elbow Surg 12(6):641-649. https://doi. org/10.1016/S1058-2746(02)86811-2

10. Bono CM, Renard R, Levine RG, Levy AS (2001) Effect of displacement of fractures of the greater tuberosity on the mechanics of the shoulder. J Bone Joint Surg Br 83(7):1056-1062. https://doi. org/10.1302/0301-620X.83B7.10516

11. Park TS, Choi IY, Kim YH, Park MR, Shon JH, Kim SI (1997) A new suggestion for the treatment of minimally displaced fractures of the greater tuberosity of the proximal humerus. Bull Hosp Jt Dis 56(3):171-176

12. Hermodsson I (1934) Roentgenologischen Studien uber die traumatischen und habituellen schulterverrenkungen nach vorn und nach unten. Acta Radiol 20:1-173

13. AtounE, Narvani A, Even Tetal (2013) Management of first-time dislocations of the shoulder in patients older than 40 years: the prevalence of iatrogenic fracture. J Orthop Trauma 27(4):190-193. https:// doi.org/10.1097/BOT.0b013e31826576f8

14. Demirhan M, Akpinar S, Atalar A, Akman S, Akalin $Y$ (1998) Primary replacement of the humeral head in iatrogenically displaced fracture-dislocations of the shoulder: a report about six cases. Injury 29(7):525-528

15. Gilbart MK, Gerber C (2007) Comparison of the subjective shoulder value and the Constant score. J Shoulder Elbow Surg 16(6):717-721. https://doi. org/10.1016/j.jse.2007.02.123

16. Kirkley S, Alvarez CAG (1998) The development and evaluation of a disease-specific quality of life measurement tool for rotator cuff disease: the western ontario rotator cuff index. J Am Acad Orthop Surg 26(6):764-772

17. Rowe CR (1988) Evaluation of the shoulder. In: Rowe C (ed) The shoulder. Churchill Livingstone, New York, pp 631-637

18. Constant CR, Murley AH (1987) A clinical method of functional assessment of the shoulder. Clin Orthop Relat Res 214:160-164. https://doi.org/10.1097/ 00003086-198701000-00023

19. Constant CR, Gerber C, Emery RJH, Søjbjerg JO, Gohlke F, Boileau P (2008) A review of the Constant score: modifications and guidelines for its use. J Shoulder Elbow Surg 17(2):355-361. https://doi. org/10.1016/j.jse.2007.06.022

20. Moroder P, Odorizzi M, Pizzinini S, Demetz E, Resch $H$, Moroder P (2015) Open Bankart repair for the treatment of anterior shoulder instability without substantial osseous Glenoid defects. J Bone Joint Surg Am 97(17):1398-1405. https://doi.org/10. 2106/JBJS.N.01214

21. Mutch J, Laflamme GY, Hagemeister N, Cikes A, Rouleau DM (2014) A new morphological classification for greater tuberosity fractures of the proximal humerus: validation and clinical implications. Bone Joint J96 B(5):646-651. https:// doi.org/10.1302/0301-620X.96B5.32362

22. Hill HA, Sachs MD (1940) The grooved defect of the humeral head. Radiology 35(6):690-700. https:// doi.org/10.1148/35.6.690
23. Samilson R, Prieto V(1983) Dislocation arthropathy of the shoulder. J Bone Joint Surg Am 65A(4):456-460

24. Deitch J, Mehlman CT, Foad SL, Obbehat A, Mallory M (2003) Traumatic anterior shoulder dislocation in adolescents. Am J Sports Med 31 (5):758-763

25. Vermeiren J, Handelberg F, Casteleyn PP, Opdecam $P$ (1993) The rate of recurrence of traumatic anterior dislocation of the shoulder. Int Orthop. https://doi.org/10.1007/BF00180449

26. Di Silvestro MD, Lo IKY, Mohtadi N, Pletsch K, Boorman RS (2007) Patients undergoing stabilization surgery for recurrent, traumatic anterior shoulder instability commonly have restricted passive external rotation. J Shoulder Elbow Surg 16(3):255-259. https://doi.org/10. 1016/j.jse.2006.09.019

27. Moroder P, Scheibel M (2017) ABC classification of posterior shoulder instability. Obere Extremität 12(2):66-74. https://doi.org/10.1007/s11678017-0404-6 